\title{
DYNAMIC MODEL AND CONTROL OF 2-DOF ROBOTIC ARM
}

\author{
Mesut HÜSEYINOĞLU ${ }^{* 1}$, Tayfun ABUT ${ }^{2}$ \\ ${ }^{* 1}$ Department of Mechanical Engineering, Dicle University, Diyarbakır, Turkey \\ ${ }^{2}$ Department of Mechanical Engineering, Mus Alparslan University, Mus, Turkey \\ *Corresponding author; mesuth@ dicle.edu.tr
}

Received: 15 December 2018; Accepted: 29 December 2018

Robotic is a relatively young field of modern technology that exceeds traditional engineering boundaries. Control of the robots is important due to the fact that it has a usage area in many areas. In this study, modelling and control of two degrees of freedom (2-DOF) robotic arm were carried out. Lagrange-Euler method was used to obtain the dynamic equations of the robot. The system was controlled in the simulation environment. Sliding-Mode Control (SMC) and Proportional-Integral-Derivative (PID) control methods were proposed to control the 2 DOF robotic arm. The saturation function is used for the chattering problem of the sliding mode control method. Both process noise and measurement noise have been applied to control the robot in conditions close to the actual ambient conditions. The control methods applied according to the results of the simulation environment were compared and the results were examined.

Key words: Sliding Mode Control, PID Control, Dynamic Model, 2-DOF Robotic Arm

\section{Introduction}

Robotic applications are widely used in engineering and technology. It is well known that industrial robots are complex, dynamically coupled, high time-dependent and high nonlinear systems. These robots are commonly used in tasks such as welding, paint spraying, correct positioning systems, etc. In these tasks, the gripper of the robotic manipulators is required to move from one place to another or to follow certain trajectories as closely as possible. The motion control of robots is difficult due to uncertainties such as load changes, friction and external disturbances, and a highly non-linear mapped and time-varying system. Therefore, the trajectory tracking problem is the most important and fundamental task in the control of robot manipulators. Many methodologies and controllers in the literature [1-5] have been developed and implemented in order to maintain precise position control and 
stability in industrial robots. Hsu and $\mathrm{Fu}[6]$ proposed an adaptive decentralized controller for trajectory monitoring of robots. The controller cannot be fully designed for every robot joint as the control inputs and all robot connections are interconnected. Yang et al. [7] have added a disturbance monitor to the adaptive decentralized controller to compensate for the combined uncertainties for each joint. The limitation of the control system has been achieved by using only some special nonlinear damping terms. The fuzzy logic-based generalized prediction control structure is applied for a robotic arm in which a study fuzzy logic-based control algorithms are preferred [8]. A robust adaptive synchronization motion controller for a 2-DOF manipulator is proposed by Dou and Wang [9]. Yao et al. [10] developed a robust adaptive controller but neglected the effects of external disturbances and non-linear friction forces. Wijesoma [11] combined variable torque control and variable structure control to implement monitoring control. Mendes and Neto [12] introduce an adaptive fuzzy control that is integrated into a hybrid force/motion control system of an industrial robot to deal with a scenario of contact between the endeffector of the robot and a given surface. Although the improved controller has relatively high stability and robustness, the controller requires a high calculation load for practical application and cannot be used for trajectory monitoring control. He et al. [13] developed an adaptive controller based on artificial neural networks to address exogenous disorders and model uncertainties of an n-DOF robot manipulator. An adaptive neural impedance controller with input saturation was designed in [14] to satisfy the model uncertainties of a robotic manipulator. Nikdel et al. [15] developed an adaptive controller to improve the tracking performance of a robotic manipulator. The proposed controller also guarantees the system stability in the existence of nonlinearity and parameter uncertainties.

The main targets in designing robot control systems are stability and low tracking error. In this study, dynamic modelling and control of a 2-DOF robotic arm were carried out. Lagrange-Euler method [16] is used to obtain the dynamic equations. The Sliding-Mode Control (SMC) and ProportionalIntegral-Derivative (PID) control methods are proposed to control the robotic arm. The control methods applied according to the results of the simulation environment were compared and their results were examined. In the next chapter, the dynamic model of the robotic arm is developed. Then, the controller design is demonstrated with numerical simulations. Finally, an overall evaluation of the results obtained is presented.

\section{Dynamic model}

The dynamic model is important as it is used in robot design, simulation and control. It is necessary to obtain the dynamic equations to implement high-performance controllers in the control of a robot. The robot which is considered in this study consists of 2 rotary joints. The dynamic model obtained by using Lagrange-Euler [16] method is given below in closed form.

$$
\begin{gathered}
M(q)[\ddot{q}]+C(q, \dot{q})[\dot{q}]+G(q)[q]=\tau-\tau_{e} \\
\tau_{e}=J^{T} F_{t o t}
\end{gathered}
$$




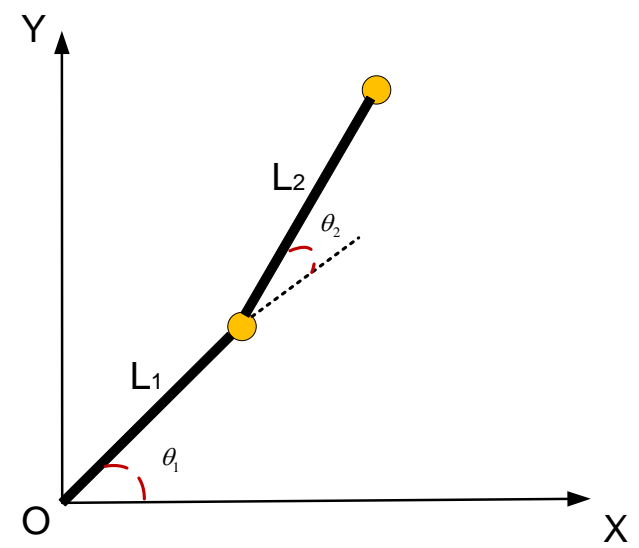

Figure 1. The model of the 2-DOF robotic arm

where, $q, \dot{q}, \ddot{q}$ and $\tau$ represent position, velocity, acceleration and control torque, respectively. $M(q) \in R^{3^{* 3}}, C(q) \in R^{3^{* 3}}$ and $G(q) \in R^{3 * 3}$ show inertial, forces of Coriolis-centrifugal and gravity matrices, respectively. $\tau_{e}$ represents the torque corresponding to the disturbing forces acting on the system from the environment. $J$ shows the Jacobian matrix and $F_{t o t}$ shows the disturbing forces affecting the system. The model of the 2-DOF robotic arm is shown in Fig. 1.

\section{Controller design}

The SMC and PID control methods were used in the position control. These methods were used in various studies in the literature [17-18]. The aim of the control systems is that the output value of the system follows the reference value. The difference between reference and output values in the system is called the error value. Controllers are tried to minimize the error.

\subsection{PID control}

PID control method shows the best performance although it is an old method used in many control applications [19]. In Eq. (3), the fundamental mathematical expression of the PID method is seen [19].

$$
u(t)=K_{p} e(t)+K_{I} \int_{0}^{\tau} e(t) d t+K_{D} \frac{d}{d t} e(t)
$$

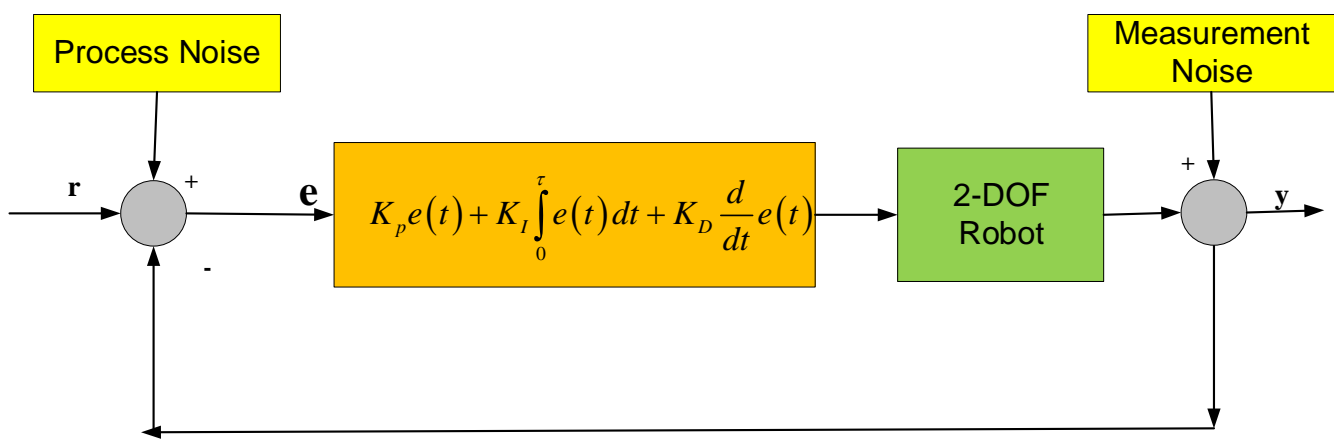

Figure 2. Block diagram of the PID feedback system

where, $u, K_{p}, K_{i}, K_{d}$ and $e$ are called the controller output, proportional gain, integral gain, differential gain and the error signal, respectively. Block diagram of the PID feedback system is shown in Fig. 2. 
Ziegler-Nichols method was used to find the PID coefficients and closed-loop control type was used in this study. The control parameters obtained by the Ziegler-Nichols method are given in $\mathrm{T}$ ab. 1 .

Table 1. Control parameters obtained by the Ziegler-Nichols method

\begin{tabular}{cccc}
\hline Control & $\mathbf{K}_{\mathbf{P}}$ & $\mathbf{K}_{\mathbf{i}}$ & $\mathbf{K}_{\mathbf{D}}$ \\
\hline $\mathrm{P}$ & $0.5 * \mathrm{~K}_{\mathrm{cr}}$ & $\infty$ & 0 \\
$\mathrm{PI}$ & $0.4 * \mathrm{~K}_{\mathrm{cr}}$ & $0.8 * \mathrm{P}_{\mathrm{cr}}$ & 0 \\
$\mathrm{PID}$ & $0.6 * \mathrm{~K}_{\mathrm{cr}}$ & $0.5 * \mathrm{P}_{\mathrm{cr}}$ & $0.125 * \mathrm{P}_{\mathrm{cr}}$ \\
\hline
\end{tabular}

Each period of the output system oscillation and the maximum gain of the oscillation are shown $\mathrm{P}_{\mathrm{cr}}$ and $\mathrm{K}_{\mathrm{cr}}$, respectively.

\subsection{SMC method}

SMC method which is used for the control of robots in various studies [20-23] was also used in this study. The joint angles of the robot were taken into account as the control variables of the system. The joint angles of the robot were checked in the presence of disturbing effects. Fig. 3 shows the block diagram of the SMC method.

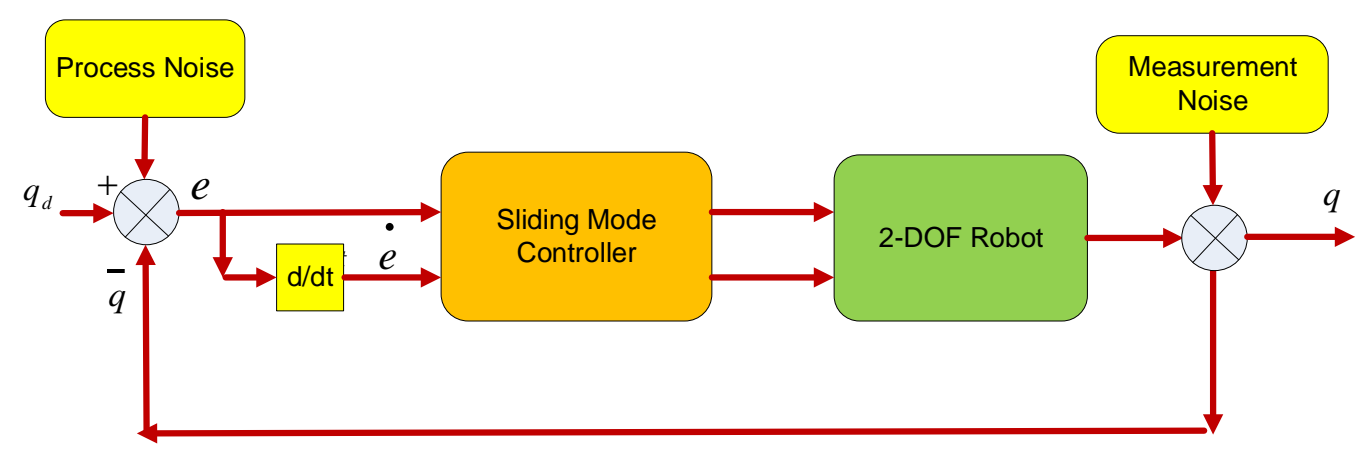

Figure 3. Control structure of the SMC method.

Error and time derivative of the error are given in Eq. (4) and Eq. (5), respectively.

$$
\begin{aligned}
& e(t)=q_{d}(t)-q(t) \\
& \dot{e}(t)=\omega_{d}(t)-\omega(t)
\end{aligned}
$$

In the above equation, qd denotes the desired joint trajectory and q shows the true trajectory. The first and second degree derivatives were used for the Eq. (4).

$$
\begin{aligned}
S & =\dot{e}-\lambda e \\
\dot{S} & =\ddot{e}-\lambda \dot{e}
\end{aligned}
$$

where, $S$ represents the sliding surface and $\lambda$ is a positive defined symmetric matrix, $u$ control signal is given in Eq. 8. The concept of sliding surface is shown in Fig. 4. 


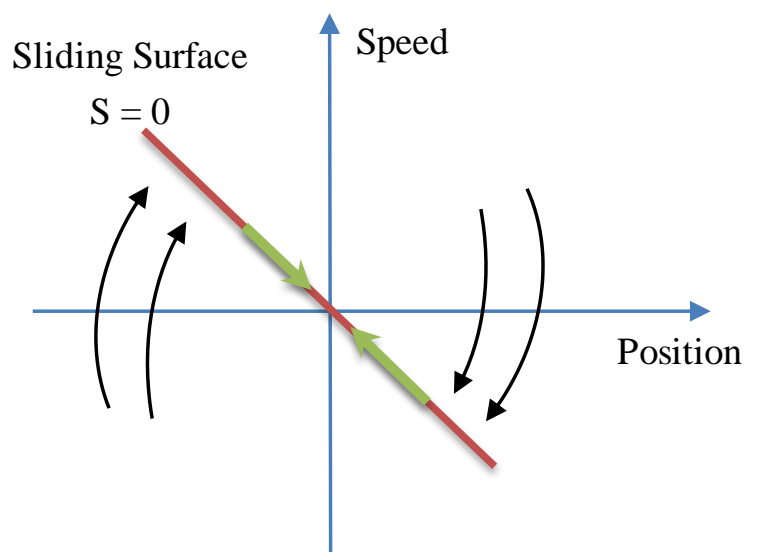

Figure 4. The concept of sliding surface.

$$
\begin{aligned}
& u=-k \times \operatorname{sign}(s) \\
& \operatorname{sat}(s / \phi)=\left\{\begin{array}{cc}
\frac{s}{\phi} & \text { if }\left|\frac{s}{\phi}\right| \leq 1 \\
\operatorname{sign}\left(\frac{s}{\phi}\right) & \text { if }\left|\frac{s}{\phi}\right|>1
\end{array}\right.
\end{aligned}
$$

Saturation function is used to solve the chattering problem, $\phi$ shows the thickness of the boundary layer, $k$ is the constant parameter and sign is a signal function and $s$ functions as a switch. Lyapunov criteria was used for the stability of the system.

\section{Simulations}

In this section, simulation studies were performed by using the dynamic equations and the performance values of the control methods are given graphically. The SMC and PID control methods are tested for their performance. Control variables are angles of $\theta_{1}$ and $\theta_{2}$ which are the basic axes of the 2-DOF robotic arm. The simulation run time was selected 30 seconds. Uncontrolled graphics of $\theta_{1}$ and $\theta_{2}$ are given in Fig. 5 and Fig. 6.

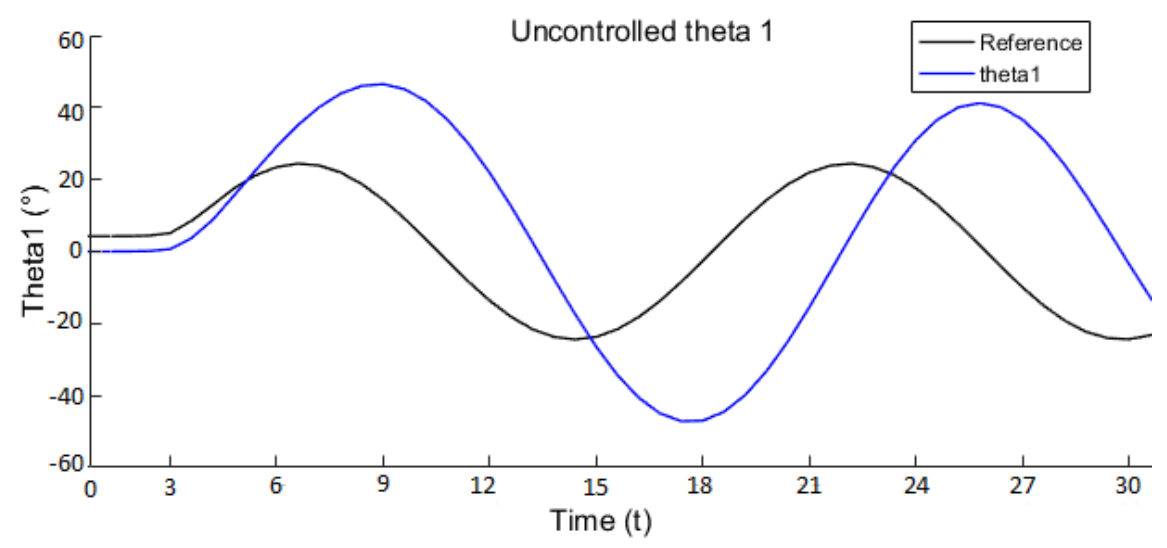

Figure 5. Uncontrolled graphic of $\theta_{1}$ 


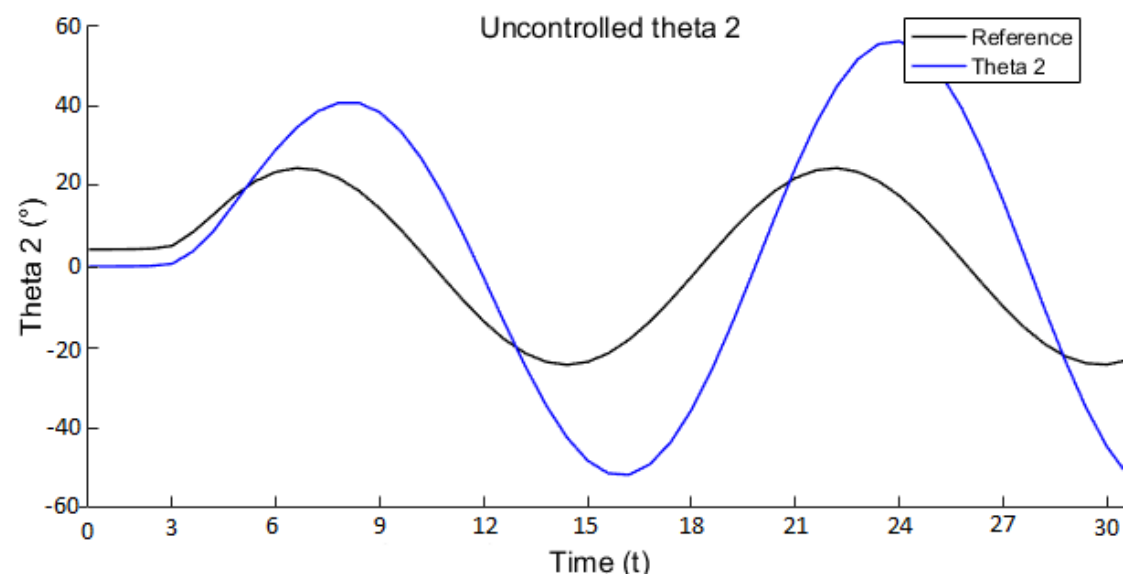

Figure 6. Uncontrolled graphic of $\theta_{2}$

As seen in the Fig. 5 and Fig. 6, $\theta_{1}$ and $\theta_{2}$ don't follow the reference inputs. Responses of $\theta_{1}$ and $\theta_{2}$ belong to PID and SMC control methods and error graphics are shown in Figs. 7-14, respectively.

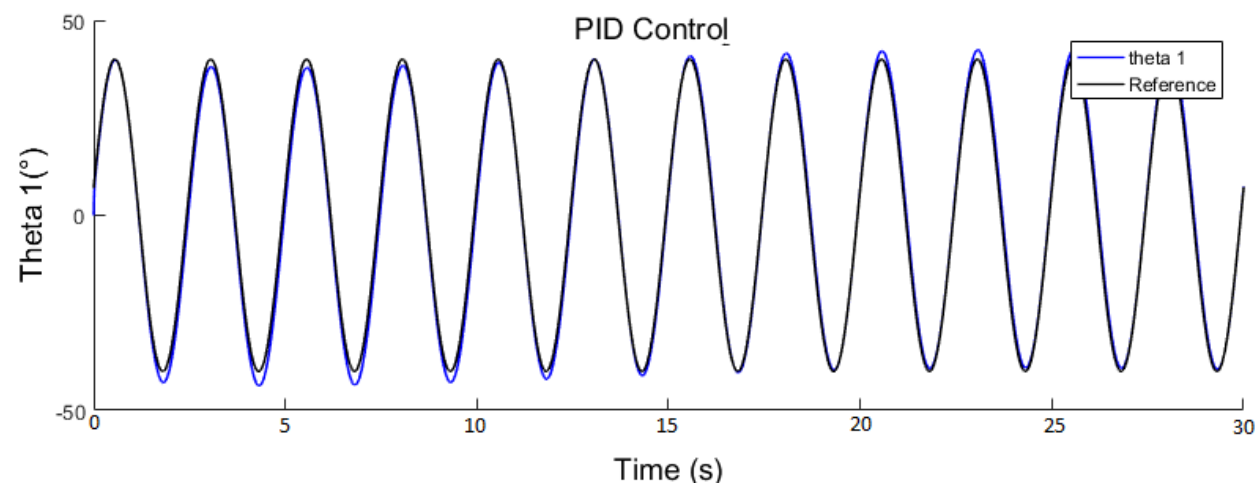

Figure 7. $\theta_{1}$ angle response obtained through the PID control method

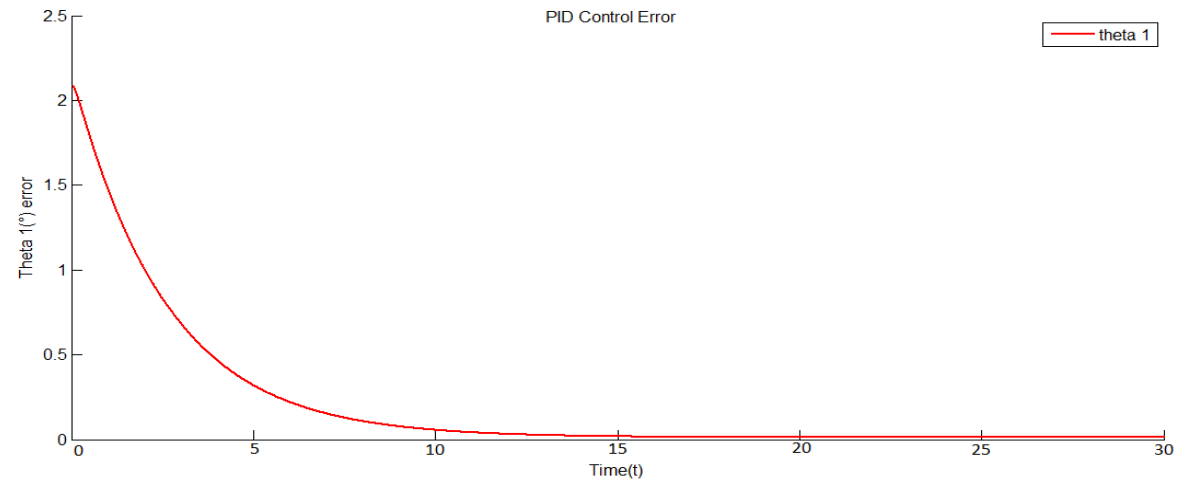

Figure 8. $\theta_{1}$ angle error response obtained through the PID control method 


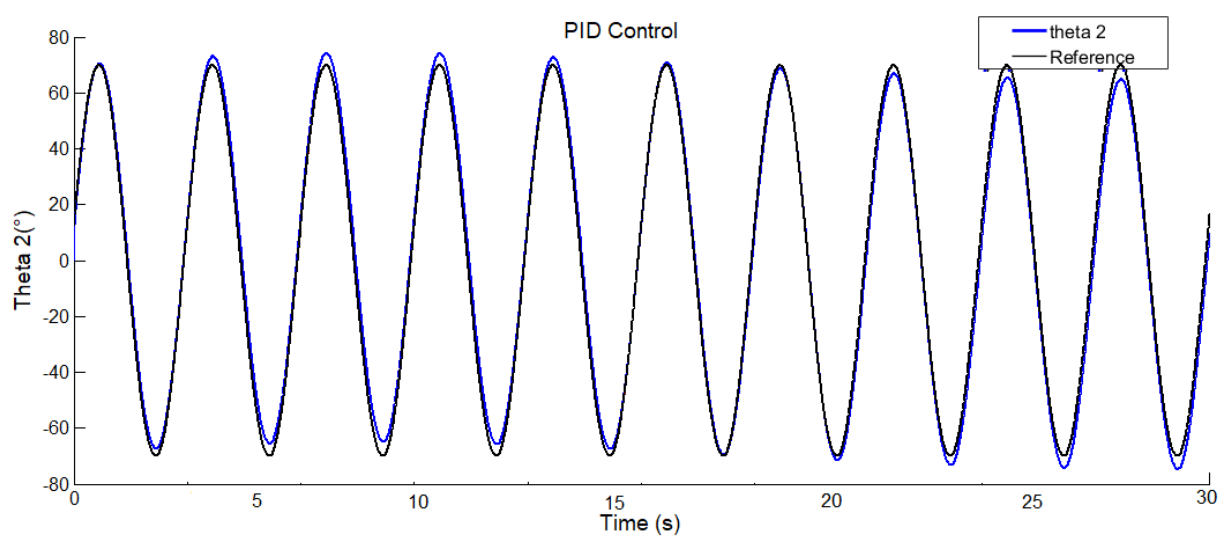

Figure 9. $\theta_{2}$ angle response obtained through the PID control method

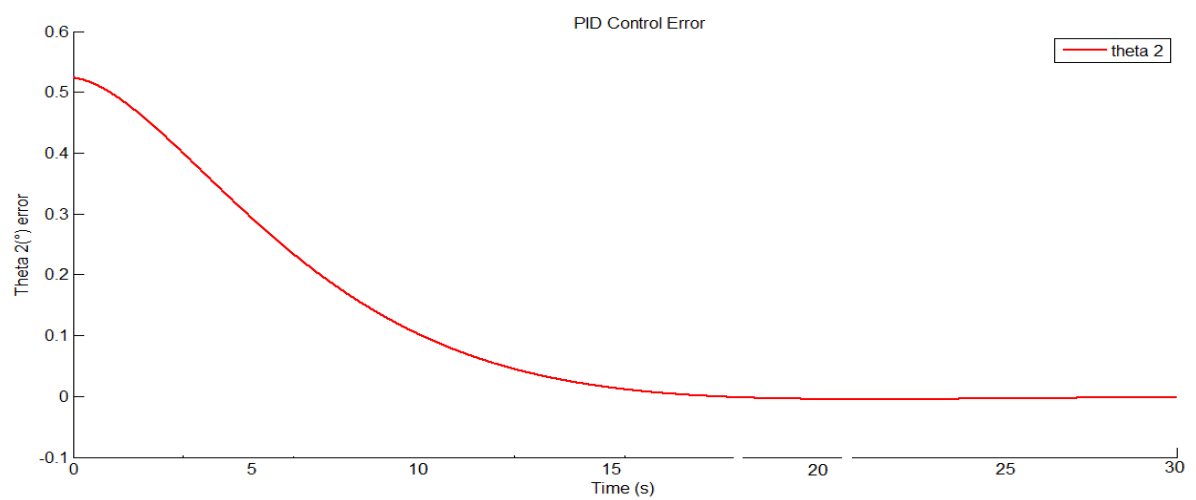

Figure 10. $\theta_{2}$ angle error response obtained through the PID control method

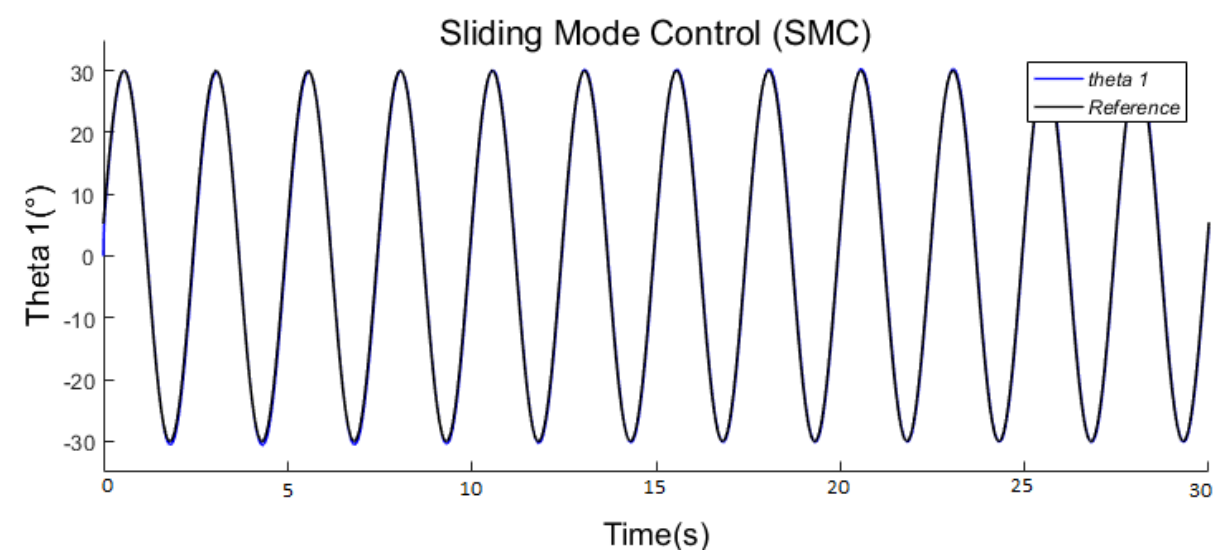

Figure 11. $\theta_{1}$ angle response obtained through the SMC method

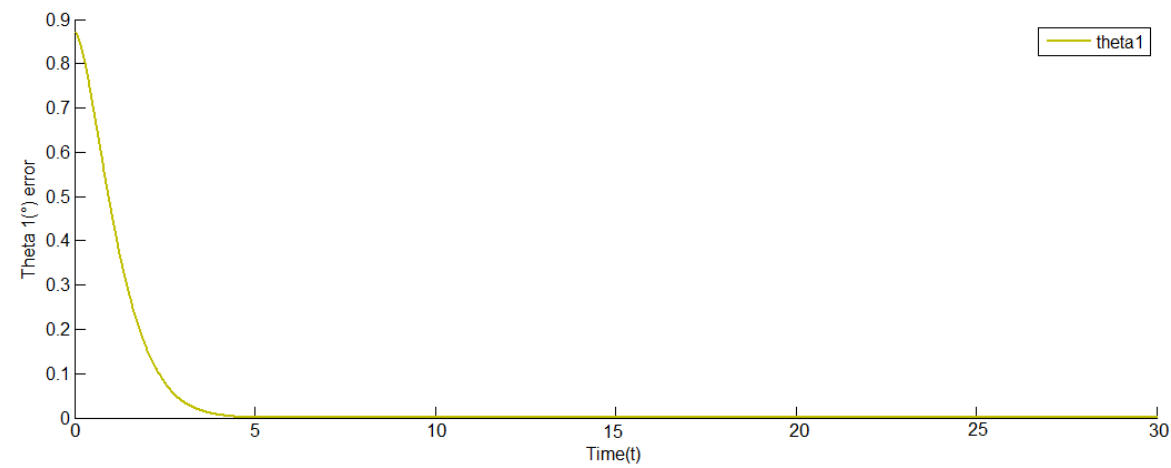

Figure 12. $\theta_{1}$ angle error response through the SMC method 


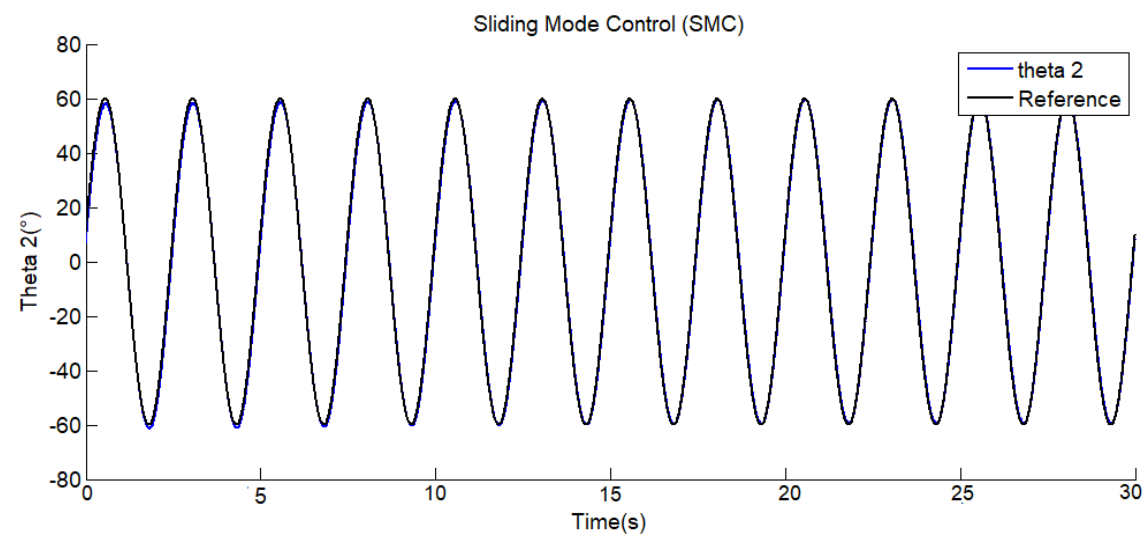

Figure 13. $\theta_{2}$ angle response obtained through the SMC method

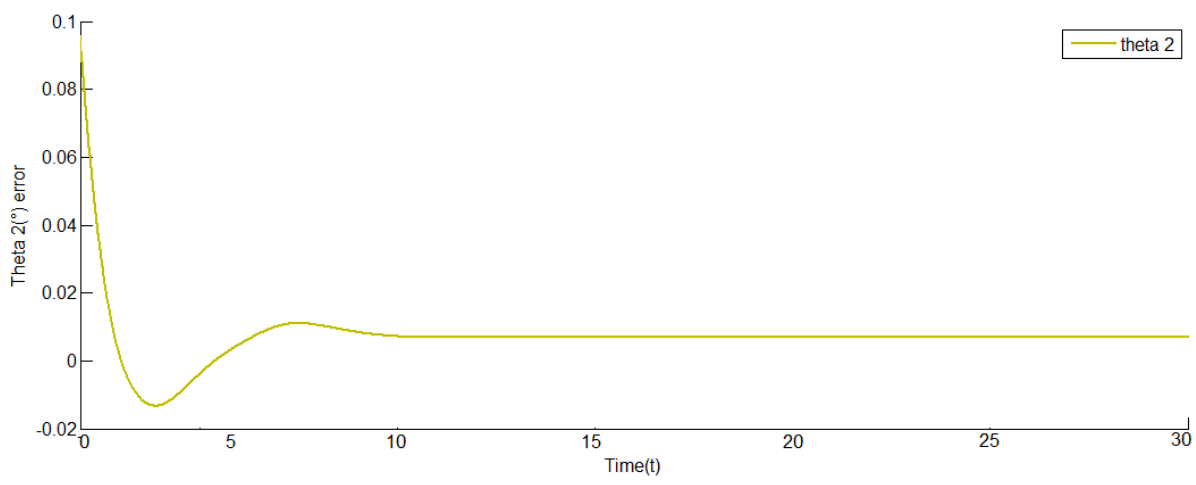

Figure 14. $\theta_{2}$ angle error response obtained through the SMC method

Fig. 15 and Fig. 16 show the torque graphics required for the 1st joint and the 2nd joint.

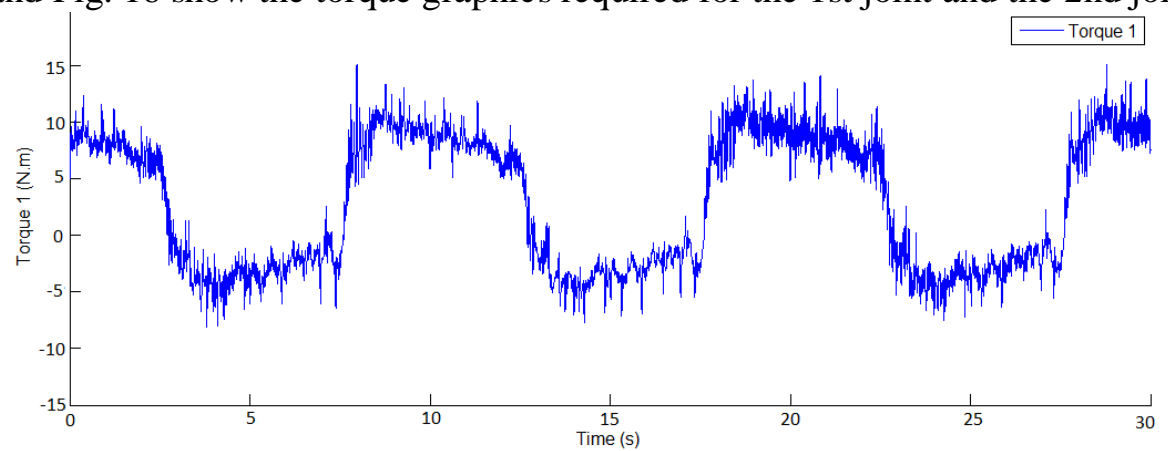

Figure 15. Torque graphic for $\theta_{1}$ angle

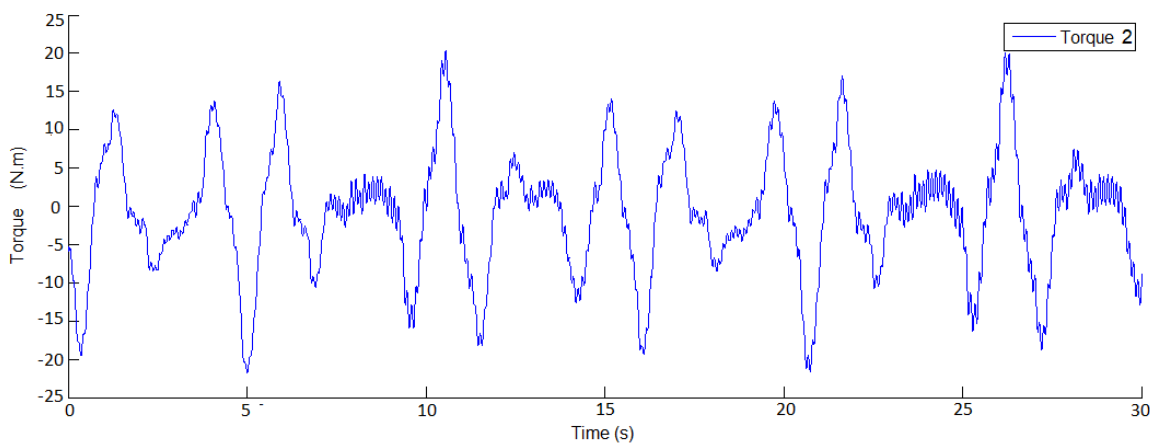

Figure 16. Torque graphic for $\theta_{2}$ angle 
As seen in figures, the PID control method generally followed the reference with greater amplitude. The PID control method has a greater settling time when considering error graphics. Similarly, as can be seen from the error graphs, SMC method gives good performance results according to PID control method.

\section{Results and discussions}

In this study, dynamic model of 2-DOF robotic arm was obtained by using Lagrange-Euler method. SMC and PID control methods were used for the control of the robotic arm. The performance of these control methods is shown in numerical studies that are performed in simulation environment. It has been seen that the chattering problem of SMC method is solved by saturation function. Both the signal noise and the measurement noise were applied to the si gnals in order to simulate the actual ambient conditions. A second order low pass filter is applied to increase the performance of the controllers in the noise environment. The cut-off frequency, damping ratio and initial run for the second order low pass filter are taken into account as $100 \mathrm{rad} / \mathrm{s}, 1$ and 0 , respectively.

As a result of the comparison of the control methods, it was observed that the controllers gave satisfactory results. The SMC method gave the best results. It is aimed to apply the proposed methods and a real system in future studies.

\section{References}

[1] Pan, L., Gao, T., Xu, F., Zhang, L., Enhanced Robust Motion Tracking Control for 6 Degree-offreedom Industrial Assembly Robot with Disturbance Adaption, International Journal of Control, Automation and Systems, 16 (2018), 2, pp. 921-928

[2] Meng, D., Moore, K. L., Robust Iterative Learning Control for Nonrepetitive Uncertain Systems, IEEE Transactions on Automatic Control, 62 (2017), 2, pp. 907-913

[3] Chaudhary, H., Panwar, V., Prasad, R., Sukavanam, N., Adaptive Neuro Fuzzy Based Hybrid Force/Position Control for an Industrial Robot Manipulator, Journal of Intelligent Manufacturing, 27 (2016), 6, pp. 1299-1308

[4] Lochan, K., Roy, B. K., Control of Two-link 2-DOF Robot Manipulator Using Fuzzy Logic Techniques: A Review, Proceedings, $4^{\text {th }}$ International Conference on Soft Computing for Problem Solving, Warsaw, Poland, 2014

[5] Piltan, F., Nabaee, A., Ebrahimi, M., Bazregar, M., Design robust fuzzy sliding mode control technique for robot manipulator systems with modeling uncertainties, International Journal of Information Technology and Computer Science, 5 (2013), 123-135

[6] Hsu, S. H., Fu, L. C., Adaptive decentralized control of robot manipulators driven by current-fed induction motors, IEEE/ASME Trans. Mechatronic, 10 (2005), 4, pp. 465-468

[7] Yang, Z. J., Fukushima, Y., Qin, P., Decentralized adaptive robust control of robot manipulators using disturbance observers, IEEE Transactions on Control Systems Technology, 20 (2012), 5, pp. $1357-1365$ 
[8] Cronin, J., Escano, J. M., Roshany-Yamchi, S., Canty, N., Fuzzy-Based Generalized Predictive Control of a Robotic Arm, Proceedings, 25 ${ }^{\text {th }}$ IET Irish Signals \& Systems Conference, 2014

[9] Dou H. B., Wang ,S. P., Robust adaptive motion/force control formotion synchronization of multiple uncertain two-link manipulators, Mechanism and Machine Theory, 67 (2013), pp. 77-93

[10] Yao, J. Y., Jiao, Z. X., Yao, B., Shang, Y. X., Dong, W. B., Nonlinear adaptive robust force control of hydraulic load simulator, Chinese Journal of Aeronautics, 25 (2012), pp.766-775

[11] Wijesoma, S. W., Richards, R. J., Robust Trajectory Following of Robots Using Computed Torque Structures with VSS, International Journal of Control, 52 (1990), 4, pp. 935-962

[12] Mendes, N., Neto, P., Indirect adaptive fuzzy control for industrial robots: a solution for contact applications, Expert Systems with Applications, 42 (2015), 22, pp. 929-935

[13] He, W., Chen, Y.,Yin, Z., Adaptive neural network control of an uncertain robot with full-state constraints, IEEE Trans. Cybern, 46 (2016), 3, pp. 620-629

[14] He, W., Dong, Y., Sun, C., Adaptive neural impedance control of a robotic manipulator with input saturation, IEEE Trans. Syst. Man Cybern.: Syst, 46 (2016), 3, pp. 334-344

[15] Nikdel, N., Badamchizadeh, M. A., Azimirad, V., Nazari, M. A., Adaptive backstepping control for an n-degree of freedomrobotic manipulator based on combined state augmentation, Robotics and Computer-Integrated Manufacturing, 30 (2017), 44, pp. 129-143

[16] Hazewinkel, M., Lagrange equations (in mechanics)-Encyclopedia of Mathematics, Springer, Netherlands, 1990

[17] Abut, T., Modeling and Optimal Control of a DC Motor, Int. J. Eng. Trends Technol., 32 (2016), 3, pp. $146-150$

[18] Ziegler, G., Nichols, N. B., Optimum settings for automatic controllers, Journal of Dynamic Systems, Measurement, and Control, 115 (1993), 2B, pp. 220-222

[19] Aström, K. J., Hägglund, T., PID controllers: theory, design, and tuning, Instrument Society of USA, 1995

[20] Bailey, E., Arapostathis, A., Simple sliding mode control scheme applied to robot manipulators, International journal of Control, 45 (1987), 4, pp. 1197-1209

[21] Utkin, V. I., Sliding mode control design principles and applications to electric drives, IEEE transactions on industrial electronics, 40 (1993), 1, pp. 23-36

[22] Utkin, V. I., Chang, H. C., Sliding mode control in electro-mechanical systems, Mathematical Problems in Engeneering, 8 (2002), 4-5, pp. 451-473

[23] Bartolini, G., Pisano, A., Punta, E., Usai, E., A survey of applications of second-order sliding mode control to mechanical systems, International Journal of control, 76 (2003), 9-10, pp. 875-892 